\title{
Korean nursing students' experiences of their first clinical practice
}

\author{
J inhyang Yang \\ Department of Nursing, Inje University, Busan, South Korea \\ Correspondence: Jinhyang Yang. Address: 633-165 Gaegum-dong, Busanjingu, Busan 614-735, South Korea. \\ Telephone: 82-51-890-6839. Fax: 82-51-896-9840. Email: jhyang@inje.ac.kr.
}

Received: J une 30, 2012

DOI : 10.5430/jnep.v3n3p128

\section{Abstract}

Background: Clinical practice in nursing education develops the students' core competence in nursing. Nursing students' experiences of their clinical practice provide deeper insight to develop an effective clinical teaching strategy in nursing education. The purpose of this study was to explore the meanings and structure related to nursing students' experiences of their clinical practice.

Methods: A qualitative approach based on van Manen's phenomenological method was used. Participants were 12 female students and three male students, ages 21 to 25 in a nursing college. Data were collected from iterative work with in-depth interviews and their field notes during the first clinical practice of eight-weeks. Each interview was tape-recorded and transcribed verbatim.

Findings: Essential themes that fit into the context of the four existential ground of body, time, space and other people emerged: body locking up, hands trembling; an obstruction-like being; feeling the patient's pain; my proud self as a future nurse; the first encounter with a serious and awkward time; increasing one's own time for self-reflection; long days but a quickly-passing week; any places with uncomfortableness; steadily growing radius of activities; nurses who and who are not worthy of emulation; but still-grateful patients; and my most reliable practice colleague.

Conclusions: The result showed that nursing students did not adapt efficiently to clinical practice and they experienced difficult learning processes. It is necessary for nursing faculty to develop effective and realistic orientation programs, support systems, and intervention programs to strengthen nursing students' competency. The lived experiences of clinical learning among nursing students provided useful insight for nursing faculty involved in nursing education.

\section{Key words}

Nursing education, Clinical practice, Nursing student, Qualitative research

\section{Introduction}

The goal of nursing education is to promote the ability of nursing students to comprehensively and systematically resolve the clients' nursing problems, through acquiring the knowledge, skill and attitude needed in nursing. Nursing education can be divided into theories and practice, and of these, the practice education would be the education that entails going out 
to actual nursing fields and observing and experiencing for oneself the lives of clients. Therefore, it can have a very significant impact on performing the role of a professional nurse upon graduation ${ }^{[1]}$.

Clinical practice is a process of applying in actuality the theories and skills learned in the classroom and practice laboratory. Nursing students, having entered school at the beginning of their adulthood, have almost no experience in being responsible for the health and well-being of others. In addition, leaving the safe and supportive teaching environments of their school, they are placed into clinical environments that are perceived as unfamiliar and complex and that have diverse human relations they need to deal with. Such experience can present difficulties in various aspects, since the students would need to deal with the nursing problems of their assigned patients in a unfamiliar environment, different from that of their school environment ${ }^{[2]}$.

With the recent multi-faceted changes in the health care environment, the argument that the clinical nursing education needs to be reviewed has been gaining momentum ${ }^{[3]}$. Clinical education needs to offer learning opportunities that will be helpful in transitioning to the role of a professional. It is imperative that clinical teaching prepares students to assume professional responsibility after graduation. One approach to clinical teaching is simulation to which students are equipped with nursing techniques and clinical decision making capabilities. Nursing students, however, still experience theorypractice gap while they undergo clinical practice which leads to dissatisfaction to the clinical component of their education ${ }^{[3,4]}$. Finding, therefore, what kind of experiences nursing students go through in their clinical practice must take precedence so that the actual practical training becomes effective.

The body of evidence on clinical practice of nursing students talks about anxiety ${ }^{[5,6]}$, learning process ${ }^{[4]}$, critical thinking process ${ }^{[7]}$, models of supervision on student ${ }^{[8]}$, cancer patient nursing ${ }^{[9]}$. These studies, however, were limited to reveal a holistic understanding of the experience with culture-specific dimension because they focused on specific topics or a part of their clinical experience. In addition, very little is known about the clinical experience of Koran nursing students, or meaning this population gives to the concept of clinical practice.

Clinical practice has important effects on the core competence of nursing students and the formation of their nursing professionalism. Strategies to minimize the difficulties students experience and to perform the efficient clinical practice training should be based on knowledge of nursing students' clinical practice experiences within their social context. The study of nursing students' clinical experiences will provide practice-specific information that will be helpful in assisting nursing educators in improving clinical practice education for nursing students. Therefore, the author applied an interpretive qualitative approach to comprehend the unique experiences of clinical practice among Korean nursing students. The goal was to explore various meanings and structure of clinical practice experiences among the students. On the basis of the findings of the study, tailored education of clinical practice for nursing students can be developed.

\section{Methods}

\subsection{Design}

This study is a qualitative research that applied the phenomenological approach of Van Manen ${ }^{\text {[10] }}$ to explore and comprehend the meanings and structure of experiences related to the clinical practice of nursing students. The research question that this study intends to address is, "What are the clinical practice experiences of the nursing students?”

\subsection{Participants}

The participants of this study were 15 third year students in a nursing college. The department where they did their practice was the general ward excluding the pediatric ward. The professor-in-charge gave orientations on clinical practice to the students and clinical instructor, and the clinical instructor provided one long clinical practice instruction session of approximately two-hours for each team three times a week. While the data collection and analysis were taking place, the 
sampling continued until reaching saturation. The age range of participants was 21 to 25 years, and, for gender, there were 12 female students and three male students. In terms of religion, there were five Protestants, two Catholics, two Buddhists and six atheists.

Participants were recruited from a pool of 92 third-year baccalaureate students from one nursing college. As third year nursing students start first clinical experiences, they were selected for this study. The author visited the professor-incharge of clinical practice in this nursing college after written and verbal permissions were obtained and the study goals were explained. After that, the author met all of the third year nursing students in the classroom before starting clinical practice and asked for voluntary participation in this study. Those who agreed to participate in the study were contacted personally, where arrangements were made for recording their field notes during the practice period and interviews, which took place after completing their first clinical practice of 8-weeks. All participants were given information on the purpose of the study, the interview procedure, confidentiality, anonymity, and their right to withdraw from the study at any time.

\subsection{Data collection and analysis}

Data were collected from individual in-depth interviews and their field notes. Initially, the researcher tried to build rapport with participants and obtain their demographic information. The interviews began with open and semi-structured questions about general events and progressed to questions about their experiences of clinical practice. The participants were asked the following questions: "Please describe your experience related to the clinical practice."; "What were the most enjoyable/difficult experiences during the clinical practice?”; "What does the clinical practice mean to you?”; “As you are going through the clinical practice, what changes have you experienced?” During the interviews, the researcher carefully observed the behavior and facial expression or tone of the participants. The researcher also took notes of her ideas and questions, the participants' non-verbal expressions, and interview highlights, all of which were discussed in the next meeting. Each interview was audio taped using recorder and transcribed verbatim.

The data collection period of this study was about 2 months from June to July 2011. Each interviewee was interviewed an average of 2-3 times and the average amount of time spent for each interview was about 1-hour ranging from 30 minutes to 1.5 hours. In addition, during the practice period, participants were encouraged to record their daily clinical practice experiences exactly how they experienced them, and after completion of clinical practice, their notes were collected. The field note offers the advantage of unfolding, in a vivid and continual manner, the day-to-day events and happenings experienced by the participants, rather than by jogging their past memories at the end of the clinical practice period.

Data analysis was accomplished by an iterative work with data collection. The use of systematic data analysis procedures which included significant statements, meanings, and an exhaustive description followed phenomenology and the procedures advanced by van Manen ${ }^{[10]}$ : (a) the study of practical experience, (b) the explication of phenomena as they present themselves to consciousness, (c) the reflection on the essential themes which characterize the phenomenon, especially in aspects of four existentials such as lived body, lived time, lived space, and lived human relation, (d) the description of the experiential meaning we live as we live them, and (e) the balance of the research context by considering parts and the whole.

The author read through the written transcripts several times line-by-line and highlighting approaches to obtain an overall understanding. The data were reviewed several more times for congruence with the identified themes. At this time, four existentials, that is corporeality, temporality, spatiality, and relationality, were considered to extract essential themes. van Manen ${ }^{[10]}$ referred to these themes as existentials which were helpful as guides for reflection in the research process. Additionally, two professors who have had experiences in phenomenological study reviewed that these themes were consistent with the significant statements. Discrepancies were discussed, and consensus was reached. Finally, the researcher validated the findings with some participants, and included the participants' remarks in the description. Checking with participants is one of the strategies for establishing credibility of the findings because qualitative research explores the participants' experiences through collaboration between researchers and participants. 


\subsection{Ethical consideration}

The consents of participants were obtained using written informed consent forms, upon explaining to them the purpose and method of research and necessity of recording the interviews. Participants were informed that the contents of their field notes and interviews would be used solely for the research, that the personal circumstances of individual participants would remain confidential, and also that the participants would be able to withdraw from participation anytime they wished. The rights of the participants were upheld and protected in each of the conducted interviews. Ethics approval by a committee, however, was not accomplished; at the time of this study, there were no institutional review boards at the university.

\subsection{Rigor}

Trustworthiness of this study was established by meeting Meadows and Morse's ${ }^{[11]}$ criteria for verification and validity. Verification was attained by literature reviews at the outset of the study, adhering to the phenomenological method, and by keeping memos and reflective journals on the decision trail. In addition, the researcher reviewed several times for congruence with the identified meanings and structure. Validity, the outcome goal of any research, was based on member checking and external reviews. The researcher validated the findings with some participants, and included the participants' remarks in the description. Additionally, two professors with experiences with phenomenological study reviewed the procedure and finding of this study, and confirmed that the meanings and structure were consistent with the significant statements. Discrepancies were discussed and consensus was reached.

\section{Findings}

In order to identify the essential meaning of experiences related to the clinical practice from the interview data of the study participants, a phenomenological reflection was conducted, by returning a number of times to the text and statements of the study participants. van Manen ${ }^{[10]}$ has proposed four fundamental existentials that can help in the process of reflection where the essential analysis of themes occurs. These four existentials provide help in the manifestation of a more basic level of meaning of the participants' lived experiences, although each of the existentials can be distinguished, they cannot be separated. Based on the lived body, time, space and relationships, the essential themes of the experiences related to the clinical practices of participants are as follows:

\section{Lived body}

\section{Body locking up, hands trembling}

Participants arrived at the clinical practice field with an anticipative excitement because they would get to observe and apply in a real clinical setting the theories and nursing skills they learned in the classroom and laboratory. Nonetheless, their simultaneous feeling was that of fear; a doubtful fear as to whether they would perform well or not. As they were faced with various situations in the practice site, the sense of embarrassment and uncertainty was felt throughout the body. Inability to properly hear the sounds when measuring blood pressure with a stethoscope or a repeated administering of a blood glucose level check due to improper readings occurred, and during the process, the expression of frustration and anger by patients further added to the embarrassment. One participant described her experiences in the field through field notes: "When preparing for injection with vial and syringe under a nurse's instruction, my hands trembled, my body froze, and my mind went blank, instead of recalling what I had learned. When the researcher observed students preparing for medication while making a round of wards, it was possible to see that students were just staring at the nurses perform their jobs, while their hands, holding an ampule or vial, were trembling.

"As I entered the patient's room to see my assigned patient, the patient or the patient's guardians looked up at me curiously, and with each step I took I felt semiconscious. Even though I said to myself, "The professor has said that vital signs are basic. So, relax! I didn't want to show that I was nervous," when actually I tried to measure 
the blood pressure of patient, I could not hear any sounds through the stethoscope. I tried again but got the same result, and when the patient asked what the blood pressure was it felt like my body was locking up. As I hesitated to give an answer, the patient scolded me. At that moment, everything became dark.”

"Because my hands shook even as I was getting just the ampule and vial ready for an injection, I could not do it properly. The nurse looked at me as if to say, 'What in the world are you doing?' While she finished readying 5 or 6 sets, I was still fumbling around on my first set."

\section{An obstruction-like being}

During the first few days after starting clinical practice, the participants were uncertain as to where they should be, where to look and what they should be doing. Despite the fact that at school the professor-in-charge gave orientations, at the clinical practice field assignments were given and the instructor made rounds in giving instructions, When faced with the actual practice, the thoughts in one's head were not arranged and the reality did not follow along naturally with one's wishes. Spending time in patient rooms would entail taking in the doubtful stares from the patient's family members, and hanging around in the nurse's station would mean being conscious of the nurses' gazes as well. As a result, the participant feels like an unnecessary obstruction in the actual practice field.

"There I was standing around the nurse's station with no sense of purpose, and then there were the nurses, physicians, and even patients who were busily moving about! When they walked by me I would simply look down and moved my body to allow them to walk past me without running into an obstacle. I couldn't help but let out a sigh and think thought that I was really just nobody who just got in people's ways.”

"On my first day, I had no idea what I needed to do, so I just kept on following the instructor. Although the second day seemed a little better, since I was following after the nurse mainly just to observe, it felt like I was just getting in the way and bothering the nurse who was busily moving about with no rest."

\section{Feeling the patient's pain}

When it was past the midpoint and almost toward the end of the practice period, the participants had become very close to the patient and the patient's family and started to feel their pain and agony. Over time, from holding the patient's hands the participants started to feel something for their patients. That something is a feeling of the moving or reverberation of the heart that could only be felt with the members of one's own family or someone very close.

"Mr. Kim, who has a first-stage stomach cancer and is assigned to me as the case study subject. Whenever I tried to check his blood pressure, he says, 'Not this arm, use this arm instead.' My heart ached so much. I was having a hard time because with the passing days I felt the patient's pain and every time I left his room I couldn't help crying."

"With what I could actually do for patients being so limited, what're hard for me to forget are the thoughts, anxiety, sensations of patients that I learned while just talking to them during the practice period."

\section{My proud self as a future nurse}

Over time, the participants started to gradually adapt to the practice situations and they transitioned from an observationcentered stage to the stage of actually trying out nursing skills. Even though participants erred and made mistakes during this process, they gained self-confidence through both small and large successes. In particular, when they performed well in front of the instructor or nurse, or patients and the patient' families, they felt indescribable joy. One participant who had such experience stated that, whenever she visited the patient's room or walked down the corridor, she felt pride as if she had already become a graduated nurse. 
"While I was following around my nurse, I was asked all of a sudden to prepare a urinary catheterization set and whether or not I could do this. Although I was trembling inside and felt so unsure, lest I would miss out on this opportunity, I said yes and asked that I be watched carefully. The patient was an elderly woman and knowing that I was a nursing student she was not too happy about what was about to happen, but when I completed the task successfully the joy I felt at that moment was indescribable. Soon after, my nurse often challenged me by asking, 'Do you think you can do this?' And, every time, I confidently answered, 'Yes, I can,' and I performed. Seeing myself walking around the patient ward, I felt proud as if I had already become a graduated nurse."

\section{Lived time}

\section{The first encounter with a serious and awkward situation}

It was very rare to see a ward nurse pleasantly greet students when they came into the ward. Most nurses appeared to be so focused on their work and almost ignored the students. When meeting the patient or the patient's family for the first time, the students would often make mistakes due to the awkwardness and fear of the situation. It is a fact that when the participants often made mistakes with patients, they lost the patient's trust toward them, thus creating an awkward atmosphere for the rest of the practice period.

"When we first said hello to the staff nurses as we entered the ward, no one returned our greetings and all we got instead was a quick once-over. In the serious and cold atmosphere, as we were wondering about what to do, we finally got to meet the head nurse."

One participant described the experience of feeling embarrassment when visiting the assigned patient's room: "When I went to look around the patient's room assigned to me, the gloomy atmosphere and the cold stares kept me from properly introducing myself and I quickly looked around and left the room."

\section{Increasing one's own time for self-reflection}

During the practice period, participants found themselves having more time than ever before for looking back on the day's events. The day-to-day practice experiences are recollected, by patient, by nurse-in-charge or at times even by the nursing tasks observed or practiced. In participants' own private rooms even, reflecting on the day's mistakes, they felt so embarrassed and blushed or at times felt hurt from scolding. As time passes, when the hurt feelings start to subside a little, participants begin to understand the position of the nurses or patients and even became resolved to showing better behaviors and acting certain ways the next time.

"Returning at the end of the day after a day of practice, the events that occurred during the day of practice involuntarily come to my mind. And, I find myself reflecting on what I had uttered and how I behaved. And, I began to see that it wouldn't be easy for my patients, who are nothing but scary and cold to me, to entrust their well-beings to a nursing students like myself."

"When I come home after a day of practice, the day's practice does not leave my mind. There are moments in which I felt so happy from my success, but there were also events which caused my feeling of embarrassment to linger. Particularly, as I carefully examine my mistakes, I cannot help but to think that I lack courage as well as prudence."

\section{Long days but a quickly-passing week}

To the participants, the day-to-day hours of practice can feel like such a long time. Enough to feel like having to stand around all day as punishment, it is the continuation of hour after another of hurting legs and not being able to make a noise even to breathe. As is such, the most anticipated hour in the day during the practice is the lunchtime. During lunch, one can sit and make noises. However, over the passing days, when they reach the end of practice in the ward and it is time to move 
on to next ward, not only about patients but also the nurses who were nothing but a scary figured the participants felt sadness about the impending farewells. The sense of remorse about not having done one's best to learn as much or not having been nicer to patients would remain with them as an enduring regret for a long time to come.

"While undergoing the day-to-day of practice I would look forward so much the finishing hour, but when the time came to end the practice in the ward, I felt very regretful. The regret of not having done my best for the patients, not asking the instructor nurse questions more aggressively, etc. all made me feel so sorry."

\section{Lived space}

\section{Any place with uncomfortableness}

It is not necessarily easy for what was learned in the classroom and practice laboratory to be applied directly to clinical practice. As the actual clinical practice starts, the participants are first filled with fears due to unfamiliar terms used at the practice site, their first meeting with health professionals, patients and families, and due to unfamiliar surroundings. Other than when they are shadowing along the instructor or nurse-in-charge, standing around the patient's room or nurse's station or hovering around the corridors was very uncomfortable and awkward. Although in fact it would be more comfortable for them to accompany patients to examination rooms or radiation department, etc., even those places are unfamiliar to participants and could be the cause of further embarrassment as they could not easily find their way out.

"Something, something, and some number, number-I have no idea what was being said. All I was able to catch was, '....something was done,' and other than that I could not understand anything during the shift change; whereas, when I hear the explanation I thought I understood a bit but when the nurse asked me something, it felt like my head was completely devoid of anything. Everywhere we went, it was scary and it felt like there were no safe places for us to go."

\section{Steadily growing radius of activities}

Over the passing days, participants discover themselves becoming able to 'hear more and see more.' They have arrived at the point of having enough poise to voluntarily go and visit the ever-scary patient's room just to say hello and something nice to the patient. They were able to do things with ease, such as asking instructors or nurses questions at the nurse's station with much less apprehension than before, checking the patient charts, and become capable of knowing where to go and visit, by oneself. As they reached the end of the practice period, they were able to understand most of what nurses said in the clinical field and even the hospital atmosphere that felt so different and awkward began to feel a little more comfortable. One participant described her experiences in the field notes as the following: "I am now three weeks into the clinical practice. The structure and places that seemed unfamiliar before are starting to become visible and understandable. I have no more problems accompanying patients to anywhere in the hospital."

"After a few weeks of the start of practice, I saw myself changing, too. No longer was I just standing around not knowing what to do, but I saw myself frequenting patients' rooms and finding something to do and even looking into the prep room, treatment area, etc. to see what was happening and what items were in these rooms.”

\section{Lived relations}

\section{Nurses who and who are not worthy of emulation}

The nurses in the clinical practice field are very impressionable figures for the participants. Some nurses not only interacted warmly with patients despite being very busy but also understood the student's situations and did the best in explaining things with a respectful attitude. When participants met a nurse who did these things, they were filled with an awe of gratitude and respect for the nurse and saw her as the future model of themselves. 
"Every day there was different nurse-in-charge who I followed around during the practice period, some nurses were very attentive to everything that patients said and always kind to them with questions like "How are you doing today?" and took interest in their well-being, whereas there were some nurses, as well, who were apathetic toward patients. If I become a nurse, I would want to become a nurse who is kindly attentive and who takes interest."

However, sometimes participants got to see a nurse who did not apply proper nursing principles, who was cold and lacking emotion, who unnecessarily burdened the students with excessive workloads or harshly criticized them, and who made students become very self-conscious. In these situations, not only did participants feel uneasy as to what they should do, but also they avowed to themselves that they would never become that kind of a nurse.

"I felt that nurses, because of their workload, treated patients with so little empathy: when visiting patients, they would do nothing but just dispense medicines; clean all of multiple fluid bottles with the same disinfectant cotton ball; or, when administering injection of iron compounds or antibiotics, never use techniques like Z-tract.”

\section{But still-grateful patients}

The patients are people who have discomfort in the mind and the body. The participants have come to develop grateful hearts toward those patients who were kind enough to encourage students to practice with a sense of ease during the process of students overcoming the fear felt in their first meeting with patients, in spite of their own suffering from illness. About their entrusting of their well-being with nursing students, who are not only inept in nursing skills but also unable to properly explain the knowledge, and allowing them to practice on themselves, students realized that this was not an easy thing to do and felt gratitude. Although there are among the patients those who complain and are apprehensive of students, the participants got to experience that, when they overcome the initial apprehension and take a step closer to patients, the patients would also gladly open their minds and reciprocate.

"Even when a patient first yelled at me to call a graduated nurse, I tried to with a smile do my best to help the patient, and later the patient even gave me snacks to eat and thanked me. His kind words provided the energy I needed when I was down and out from tiredness, and to that patient, I felt a special thanks.”

"There were those patients and their families who were extra nice to me during my practice period and, thanks to them, I was able to practice with ease during my difficult times."

\section{My most reliable practice colleague}

The participants felt that one of the most helpful persons during the difficult practice period was their colleague. Even those who were not close before the practice period came, as they practiced together in the same ward, they became very close and supportive of one another. When performing a specific nursing skill at the side of their practice colleague, the participant was able to muster up more courage. Even when undergoing difficult times due to mistakes or being talked to by nurses or assigned patients, the participant was a lot easier to bear with a fellow student nurse. Participants became aware how valuable they were to one another as the practice period came to its end.

"When I was assigned a patient, having my friend being assigned with a patient nearby allowed me to stay close with my friend and this always let me feel at ease. When my friend was with me I took comfort even as I was being scolded for wrongdoings, and the feeling of my sadness from practicing by myself was double when I was alone. When my friend was with me I was confident in taking vital signs, but I was very fearful when I had to do it alone. In reflection as I completed my practice period, I felt so much gratitude toward my practice colleagues who provided me the needed strength." 


\section{Discussions}

The participants of this study who took part in clinical practice were found to be experiencing themselves and the surrounding world through a filter called clinical practice. The fundamental level of meanings of the experiences related to the clinical practices of participants could be reflected from the aspects of physicality, temporality, spatiality and relationality. The main focuses of this discussion, are the experiences of the participants which should gain attention in nursing education.

The participants, as they first embarked on clinical practice, felt a sense of being overwhelmed by the clinical environment despite the professor-in-charge providing orientations regarding the overall clinical practice and real practice environment. In a hospital environment, due to the shock from vague boundaries and an unfamiliar atmosphere, apathy of health professionals or patients and condescending attitude, difficulty of communication problems, etc., there can be corporeal, temporal, spatial, and relational difficulties such as "an obstruction-like being", "the first encounter with serious ad awkward situation", "any place with uncomfortableness", and "nurses who are not worthy of emulation". These findings were consistent with the results of studies in Iran and Turkey ${ }^{[6,9]}$ that reported about the anxiety and communication problems of nursing students in the initial clinical practice environment. Korean nursing students in other study also experienced confusions of reality shock and loss of human dignity in their clinical learning ${ }^{[1]}$. In addition to factors such as the clinical environment and practice preparation, the participants in this study identified institutional and cultural aspects that influence their experiences. In the case of Korea, most nurses are in reality put in charge of a number of patients that exceed appropriate number of patients and since they are not allowed to hold two full-time jobs, they are not able to fully function as a clinical instructor. The participants felt caught between inaccessible instructors and staff nurses unwilling to supervise them. In cultural context, the traditional education in Korea was shown to be one of the factors that hinder effective clinical practice of students. Fundamental beliefs, such as "Students are supposed to study quietly," "One must follow the given learning environment," and "Teachers are supposed to be strict with students," are influenced by the traditional Confucian culture. These values have gradually faded due to the Westernization of Korean education. However, this study found that these concepts were still rooted in traditional Korean education and delayed nursing students involving actively in their clinical setting. The students in this study often demonstrated that they were just staring at the nurses perform their jobs without any question and standing around the nurse's station with no sense of purpose. Some nurses seldom returned students' greetings and responded with a quick once-over instead, and even harshly criticized them. This cultural context is supported by other study in Taiwan which refers to design nursing educational programs that can close theory-practice gap through the investigation on Confucian tradition rooted in Chinese education ${ }^{[12]}$. Therefore, the nursing educators need to have an in-depth understanding of anxiety experienced by the students during clinical practice and facilitate for sufficient educational interventions to take place.

As the fear, restlessness and anxiety of the initial stage of practice gradually wane and as specific nursing activities are observed and practiced, participants undergo experiences of confusion and conflict stemming from the differences in theories and actual practice. Nursing students, when they observe nurses being apathetic towards or not supportive of patient or students and not doing proper and accurate work based on their being busy as an excuse, will be impacted negatively on what their future image for an ideal nurse is, along with the doubt about the nursing profession itself. This result is consistent with those of other studies ${ }^{[3,13,14]}$ that reported the clinical practice experience of nursing students as a sense of gap between theories and actual practice, confusion of the identity of nursing, chaos coming from various dynamic models. The clinical practice of nursing students is an unclear learning transition that entails role conflicts and vague boundaries $^{[15]}$.

At the point of completion of a school term's practice period, participants experienced a sense of pride from their successful nursing activities. Moreover, they underwent more and more positive experiences from improved health professionals and patients' relationships, adaptation to the practice environment, and support of practice colleagues. Such experiences further solidified the nursing identity and nursing spirit, and also provided positive anticipation and active participative attitudes for follow-on practices. Therefore, in order to facilitate nursing students to undergo a successful 
transition, clinical practices that are strongly related to theories need to be provided ${ }^{[4]}$, receiving respect and support from professors or clinical instructors is needed ${ }^{[16]}$, and positive relationships among colleagues would need to be strengthened ${ }^{[17]}$. Additionally, for nursing students to raise their senses of salience, cooperation and responsibility as well in clinical practice, rather than staying in the observation stage, it would be important to increase actual practice experience under the supervision of nurses or clinical instructors ${ }^{[8]}$.

Further, as they approached the end of the practice period, participants reflected on their attitude and behavior, conflict situation, etc. during practice and took time to supplement their shortcomings or to re-establish who their role models were. In other studies ${ }^{[18]}$ as well, the fact remains that nursing students were re-establishing the role of a professional, despite the many conflicts and confusion as they finished up their clinical practice. In order for the clinical practice of nursing students to become an effective learning process, the connectivity between knowledge-based reflective thinking and experience-based learning is being pointed out as critical ${ }^{[4]}$.

The clinical practice of participants is a stage in the learning transition to become a nurse, and clinical competence is not a state but rather an ongoing process ${ }^{[19]}$. Positive experiences during this stage can be a foundation for achieving successful practice and, eventually, can be parlayed into becoming a great professional nurse. In order for such a foundation to occur successfully, a clear understanding about and sufficient sharing of the purpose of clinical practice between professors and clinical instructors or nurses are needed ${ }^{[20]}$. In addition, the development of standardized clinical practice education programs that have the needs of the nursing students reflected is needed.

\section{Conclusions}

In this study, despite starting on the first clinical practice after receiving orientations on a clinical practice, the participants did not adapt efficiently to clinical practice, and they experienced difficult and vague learning processes from physical, temporal, spatial and relational aspects. This study discovered that their experiences were influenced not only by environmental and individual factors but also by institutional factor and the Korean educational culture rooted in Confucianism. Nursing educators' awareness of and sensitivity to nursing students' perspectives could facilitate the understanding of their experiences of the first clinical practice, and development of teaching strategies.

Based on the findings, the current author wishes to suggest effective strategies of the practice education: First, to facilitate for nursing students to adapt to the clinical practice environment more rapidly while minimizing hardship, it is thought that effective and realistic orientation programs that would be helpful for all the students and nursing educators need to be developed. Second, since during the practice period the participants can experience confusion and conflict coming from the differences in theories and actual practice, continuing education and control by professors and clinical instructors are needed and standardized clinical teaching programs with an ample number of clinical instructors would need to be developed. Third, in order to strengthen the individual capacity of nursing students, along with the build-up of co-support systems including professors, clinical instructors, nurses, and practice colleague, intervention programs including interpersonal relation skills, situational coping skills, and competency assessment systems are needed. Finally, it is viewed that nursing educators should provide practical help for the clinical practice experience of nursing students, through empathetic understanding and supportive counseling.

Further studies are needed to explore nursing students' experiences at the intense level of clinical practice by means of longitudinal phenomenological study due to the limitations of this study's investigating their experiences mainly at the beginning level. Additionally, the author suggests that future studies would need to examine in greater depth the cultural differences between the East and the West through ethnographic study.

\section{References}

[1] Shin KR. The meaning of the clinical learning experience of Korean nursing students. J Nurs Edu. 2000; 39(6): 259-265. 
[2] Kim MA, Kim HE, Nam SH. Perception types of nursing students to clinical education: Q methodological approach. J Korean Acad Adult Nurs. 2001; 13(2): 327-339.

[3] Hickey MT. Baccalaureate nursing graduates' perceptions of their clinical instructional experiences and preparation for practice. $\mathrm{J}$ Prof Nurs. 2010; 26(1): 35-41. PMid: 20129591 http://dx.doi.org/10.1016/j.profnurs.2009.03.001

[4] Andersson PL, Edberg AK. Swedish nursing students' experience of aspects important for their learning process and their ability to handle the complexity of the nursing degree program. Nurse Educ Today. 2012; 32(4): 453-457. Epub 2011 Jun 8. PMid: 21652124 http://dx.doi.org/10.1016/j.nedt.2011.05.011

[5] Melincavage SM. Student nurses' experiences of anxiety in the clinical setting. Nurse Educ Today. 2011; 31(8): 785-789. PMid: 21641701 http://dx.doi.org/10.1016/j.nedt.2011.05.007

[6] Sharif F, Masoumi S. A qualitative study of nursing students experiences of clinical practice. BMC Nurs. 2005; 4(6): 1-7. PMid: 16280087 http://dx.doi.org/10.1186/1472-6955-4-6

[7] Lechasseur K, Lazure G, Guilbert L. Knowledge mobilized by a critical thinking process deployed by nursing students in practical care situations: a qualitative study. J Adv Nurs. 2011; 67(9): 1930-1940. PMid: 21466580 http://dx.doi.org/10.1111/j.1365-2648.2011.05637.x

[8] Hellström-Hyson E, Mårtensson G, Kristofferzon ML. To take responsibility or to be an onlooker. Nursing students' experiences of two models of supervision. Nurse Educ Today. 2012; 32(1): 105-110. PMid: 21388721 http://dx.doi.org/10.1016/j.nedt.2011.02.005

[9] Yildiz H, Akansel N. Beginning level nursing students' experiences with cancer patients in their first clinical placement: a qualitative appraisal in Turkey. Asian Pac J Cancer Prev. 2011; 12(10): 2611-2615. PMid: 22320962

[10] van Manen, M. Researching lived experience: human science for an action sensitive pedagogy. 2nd ed. Ontario: The Althouse Press; 1997.

[11] Meadows LM, Morse JM. Constructing evidence within the qualitative project. In Nature of Qualitative Evidence. JM Morse, JM Swansen, AJ Kuzel, ed. Thousand Oaks, CA: Sage, 2001: 187-200.

[12] Yang WP, Chao CS, Lai WS, Chen CH, Shih YL, Chiu GL. Building a bridge for nursing education and clinical care in Taiwan Using action research and Confucian tradition to close the gap. Nurse Educ Today. 2012; Apr 3. [Epub ahead of print] PMid: 22480604 http://dx.doi.org/10.1016/j.nedt.2012.02.016

[13] Romyn DM, Linton N, Giblin C, Hendrickson B, Limacher LH, Murray C, Nordstrom P, Thauberger G, Vosburgh D, Vye-Rogers L, Weidner A, Zimmel CM. Successful transition of the new graduate nurse. Int J Nurs Educ Scholarsh. 2009; 6(1): Article 34. Epub 2009 Oct 28. PMid: 19883374 http://dx.doi.org/10.2202/1548-923X.1802

[14] Tucker K, Wakefield A, Boggis C, Lawson M, Roberts T, Gooch J. Learning together: clinical skills teaching for medical and nursing students. Medical Education. 2003; 37(7): 630-637. PMid: 12834421

[15] Holland K. A journey to becoming: the student nurse in transition. J Adv Nurs. 1999; 29(1): 229-236. PMid: 10064303

[16] Magnussen L, Amundson MJ. Undergraduate nursing student experience. Nursing \& Health Sciences. 2003; 5(4): 261-267. PMid: 14622377

[17] Fenwick J, Hammond A, Raymond J, Smith R, Gray J, Foureur M, Homer C, Symon A. Surviving, not thriving: a qualitative study of newly qualified midwives' experience of their transition to practice. J Clin Nurs. 2012; 21(13-14): 2054-2063. PMid: 22672463 http://dx.doi.org/10.1111/j.1365-2702.2012.04090.x

[18] Park MY, Kim SY. A qualitative study of nursing students' first clinical experience. J Korean Acad Nurs Edu. 2000 ; 6(1): 23-35.

[19] Lejonqvist GB, Eriksson K, Meretoja R. Evidence of clinical competence. Scand J Caring Sci. 2012; 26(2): 340-348. PMid: 22059740 http://dx.doi.org/10.1111/j.1471-6712.2011.00939.x

[20] Slaughter-Smith C, Helms JE, Burris R. Nursing staff perceptions of student contributions in clinical settings. J Nurs Educ. 2012; 51(1): 54-57. PMid: 22132717 http://dx.doi.org/10.3928/01484834-20111130-02 